\title{
Antenatal Magnesium Sulfate Reduced Intestinal Morbidities Requiring Surgery in Preterm Infants With Extremely Low Gestational Age: A Retrospective Cohort Study
}

\section{Seh Hyun Kim}

Seoul National University College of Medicine https://orcid.org/0000-0001-8686-1909

Yoo-Jin Kim

Seoul National University College of Medicine

\section{Seung Hyun Shin}

Seoul National University College of Medicine

Hannah Cho

Seoul National University College of Medicine

Seung Han Shin ( $\nabla$ revival421@snu.ac.kr)

https://orcid.org/0000-0002-7008-4073

\section{Ee-Kyung Kim}

Seoul National University College of Medicine

Han-Suk Kim

Seoul National University College of Medicine

\section{Subeen Hong}

Seoul National University College of Medicine

\section{Seung Mi Lee}

Seoul National University College of Medicine

\section{Research article}

Keywords: magnesium sulfate, extremely premature infant, necrotizing enterocolitis, spontaneous intestinal perforation

Posted Date: May 21st, 2020

DOI: https://doi.org/10.21203/rs.3.rs-29795/v1

License: (c) (i) This work is licensed under a Creative Commons Attribution 4.0 International License. Read Full License 


\section{Abstract}

Background Antenatal magnesium sulfate is widely used as a tocolytic, for maternal seizures, and for seizure prophylaxis in preeclampsia. Recent studies have suggested that antenatal magnesium sulfate use is associated with favorable neurodevelopmental outcomes in preterm infants. However, there are concerns regarding the neonatal effects of antenatal magnesium sulfate, especially regarding gastrointestinal morbidities. This study aims to explore the effects of antenatal magnesium sulfate on intestinal morbidities requiring surgery in preterm infants.

Methods This was a retrospective cohort study of 181 preterm infants who were born at less than 28 weeks of gestational age. Subjects were categorized as infants exposed to antenatal magnesium sulfate and those not exposed to antenatal magnesium sulfate.

Results Antenatal magnesium sulfate was associated with a lower incidence of surgical conditions of the intestine (OR $0.393,95 \% \mathrm{Cl} 0.170-0.905)$. Multivariate analysis showed that the duration of antenatal magnesium sulfate use was associated with surgical conditions of the intestine (adjusted OR 0.766, 95\% Cl 0.589-0.997). In the < 26 weeks of gestational age subgroup, use of antenatal magnesium sulfate was significantly associated with decreased intestinal morbidities requiring surgery (adjusted OR $0.234,95 \% \mathrm{Cl} 0.060-0.922$ ).

Conclusion Antenatal magnesium sulfate use appears to have a protective effect on intestinal morbidities requiring surgery in preterm infants in a duration-dependent manner. Association of antenatal magnesium sulfate use and decreased intestinal morbidities requiring surgery was more distinct in preterm infants $<26$ weeks of gestational age.

\section{Background}

Antenatal magnesium sulfate $\left(\mathrm{MgSO}_{4}\right)$ has been widely used as a tocolytic and for the treatment of eclampsia.[1] Since randomized control trials showed that antenatal $\mathrm{MgSO}_{4}$ is associated with a reduced risk of CP in surviving infants without major adverse outcomes[2-5], the short-term use of $\mathrm{MgSO}_{4}$ for fetal neuroprotection before preterm delivery has been recommended.[6, 7] Recent systematic reviews concluded that the administration of intravenous $\mathrm{MgSO}_{4}$ to mothers who are at risk of early preterm delivery reduced the risk of neurodevelopmental disability in their surviving children.[8, 9]

However, the US Food and Drug Administration has advised against the use of $\mathrm{MgSO}_{4}$ injections for more than 5-7 days when intending to stop preterm labor in pregnant women because $\mathrm{MgSO}_{4}$ has the potential to cause skeletal abnormalities in developing babies.[6] There have also been several concerns regarding the adverse effects of antenatal $\mathrm{MgSO}_{4}$ on the neonatal outcomes of preterm infants.[10-12] In a small randomized controlled study, higher levels of umbilical cord ionized magnesium at delivery were associated with adverse outcomes.[11] A secondary analysis of neonates $<26$ weeks of age in a multicenter randomized trial for neuroprotection showed that antenatal $\mathrm{MgSO}_{4}$ was associated with an increased risk of death or severe necrotizing enterocolitis (NEC).[10] However, the association between antenatal $\mathrm{MgSO}_{4}$ and morbidities of the gastrointestinal (GI) tract in preterm infants is still controversial in extremely preterm infants.[13]

Therefore, our study aims to explore the effects of antenatal $\mathrm{MgSO}_{4}$ on the neonatal outcomes of preterm infants, including intestinal morbidities requiring surgical interventions.

\section{Methods}


This was a retrospective cohort study of preterm infants who were born at less than 28 weeks of gestation and who were admitted to the Seoul National University Children's Hospital neonatal intensive care unit between January 2011 and December 2015. Infants with major congenital anomalies and maternal preeclampsia were excluded from the study population. One patient who experienced iatrogenic gastric perforation was excluded. They were categorized as infants with antenatal $\mathrm{MgSO}_{4}$ and without antenatal $\mathrm{MgSO}_{4}$. Indications of antenatal $\mathrm{MgSO}_{4}$ included preterm labor and neuroprotection. The protocol for the antenatal $\mathrm{MgSO}_{4}$ treatment of preterm labor was a loading dose of $4 \mathrm{~g}$ infused over 30 minutes followed by a maintenance dose of $2 \mathrm{~g}$ per hour, which could be titrated according to the effect. For neuroprotection of the fetus, a loading dose of $6 \mathrm{~g}$ infused over 30 minutes followed by a maintenance dose of $2 \mathrm{~g}$ per hour was used.

Medical records of perinatal factors, including the cumulative dose of antenatal $\mathrm{MgSO}_{4}$ and the duration of antenatal $\mathrm{MgSO}_{4}$ during the last 7 days of pregnancy, as well as the maternal level of serum magnesium before delivery, were reviewed and analyzed. Data on the neonatal factors and outcomes, including the neonatal blood magnesium level and intestinal injuries, such as NEC, spontaneous intestinal perforation (SIP), and meconium obstruction (MO) requiring surgery, were collected. Data on respiratory distress syndrome, patent ductus arteriosus (PDA), bronchopulmonary dysplasia (BPD), sepsis, intraventricular hemorrhage (IVH), retinopathy of prematurity (ROP), hypotension during the first week, ibuprofen use during the first week, postnatal steroid use, duration of invasive ventilation and time to full feeding were also collected.

Intestinal morbidity requiring surgery was considered when surgical intervention was conducted for NEC, SIP or MO. NEC was diagnosed according to Bell's staging criteria and SIP when isolated bowel perforation was present without evidence of NEC or MO [14]. MO was suspected when premature infants had problems with meconium passage accompanied by abdominal distension and feeding intolerance. It was diagnosed if persistent or progressive gaseous bowel distension was noted on plain radiography, along with the presence of hypoechoic meconium-filled bowel loops and distended proximal bowel loops observed by sonography.[15, 16] Glycerin enema was used as the first-line therapy for a few days, and ultrasonography-guided water-soluble contrast enema was performed if the condition was not resolved. If contrast enema failed to relieve the obstruction, surgical intervention was carried out.

Statistical analysis was performed with STATA version 11.0. Wilcoxon rank-sum tests for continuous data and chi square tests for categorical data were used. A $P$ value $<0.05$ was considered statistically significant in all analyses. Univariate logistic regression analysis was conducted for intestinal injury requiring surgery, and factors with $p<0.10$ in the univariate analysis were included in multivariate analysis to evaluate the association between maternal $\mathrm{MgSO}_{4}$ use and intestinal injury requiring surgery. Next, duration of $\mathrm{MgSO}_{4}$, cumulative dose of $\mathrm{MgSO}_{4}$, maternal $\mathrm{Mg}$ level and neonatal Mg level were used in the multivariate logistic regression analysis. Subgroup analysis of those born before 26 weeks of gestation was also conducted.

\section{Results}

During the study period, 202 infants born at less than 28 weeks of gestational age (GA) were admitted to the Seoul National University Hospital neonatal intensive care unit. Four infants with major congenital anomalies and sixteen with preeclampsia were excluded from the study population. Among 181 infants, 109 (60.2\%) were exposed to antenatal $\mathrm{MgSO}_{4}$, including 100 infants for preterm labor and 9 infants for neuroprotection (Fig. 1). The GA (25.6 vs. 26.3 weeks) and birthweights (720 vs. 850 grams) were comparable between the no antenatal $\mathrm{MgSO}_{4}$ group and the antenatal $\mathrm{MgSO}_{4}$ group (Table 1). A higher cesarean section rate was found in the no antenatal $\mathrm{MgSO}_{4}$ group $(54.2$ 
vs. $34.9 \%, P=0.015)$. The maternal magnesium level was higher in the antenatal $\mathrm{MgSO}_{4}$ group $(1.8 \mathrm{vs} .3 .2 \mathrm{mg} / \mathrm{dl}, P<$ 0.001).

Table 1

Demographics of the study population according to the antenatal administration of magnesium sulfate

\begin{tabular}{|c|c|c|c|}
\hline & No antenatal $\mathrm{MgSO}_{4}(\mathrm{n}=72)$ & Antenatal $\mathrm{MgSO}_{4}(\mathrm{n}=109)$ & $P$ value \\
\hline GA (week) & $25.6(24-26.9)$ & $26.3(24.4-27.4)$ & 0.172 \\
\hline $\mathrm{GA}<26$ weeks & $40(55.6)$ & $46(42.2)$ & 0.095 \\
\hline Birthweight (gram) & $720(595-950)$ & $850(610-1000)$ & 0.140 \\
\hline SGA & $6(8.3)$ & $11(10.1)$ & 0.798 \\
\hline $\mathrm{C} / \mathrm{S}$ & $39(54.2)$ & 38 (34.9) & 0.014 \\
\hline Male & $30(41.7)$ & $60(55.1)$ & 0.095 \\
\hline PPROM & $40(55.6)$ & $56(51.4)$ & 0.649 \\
\hline hCAM & 35 (48.6) & $61(56)$ & 0.363 \\
\hline AS $1 \mathrm{~min}$ & $2.5(1-5)$ & $3(1-5)$ & 0.423 \\
\hline AS 5 min & $5(3-7)$ & $6(4-7)$ & 0.083 \\
\hline Antenatal steroid & $58(80.6)$ & $92(84.4)$ & 0.548 \\
\hline Multiple birth & $47(65.3)$ & $68(62.4)$ & 0.753 \\
\hline Cumulative Mg dose (g) & - & $38.3(8.7-123.6)$ & - \\
\hline Maternal Mg level (mg/dl) & $1.8(1.7-2.5)$ & $3.2(2.2-3.9)$ & $<0.001$ \\
\hline \multicolumn{4}{|c|}{$\begin{array}{l}\text { MgSO }_{4} \text {, magnesium sulfate; GA, gestational age; SGA, small for gestational age; C/S, cesarean section; PPROM, } \\
\text { preterm premature rupture of membrane; hCAM, histologic chorioamnionitis; AS, Apgar score }\end{array}$} \\
\hline
\end{tabular}

The neonatal magnesium level was higher in the antenatal $\mathrm{MgSO}_{4}$ group (1.8 vs. $\left.2.9 \mathrm{mg} / \mathrm{dl}, P<0.001\right)$. There were no significant differences in neonatal morbidities in terms of respiratory distress syndrome, hypotension during the first week of life, moderate to severe BPD, sepsis, severe IVH and ROP requiring operation (Table 2). NEC and surgical NEC were comparable between the two groups. The incidence of SIP was higher in the no antenatal $\mathrm{MgSO}_{4} \mathrm{group}(5.6 \%$ vs. $0 \%, P=0.024)$. Any intestinal morbidities requiring surgery $(22.2 \%$ vs. $10.1 \%, P=0.033)$ were lower in the antenatal $\mathrm{MgSO}_{4}$ group. The duration of invasive ventilation and the time to full enteral feeding were not different between the two groups. 
Clinical courses and neonatal outcomes of the study population

Table 2.

\begin{tabular}{|llll|}
\hline & $\begin{array}{l}\text { No antenatal } \mathrm{MgSO}_{4}(\mathrm{n}= \\
72)\end{array}$ & $\begin{array}{l}\text { Antenatal } \mathrm{MgSO}_{4}(\mathrm{n}= \\
109)\end{array}$ & $\begin{array}{l}\mathrm{P} \\
\text { value }\end{array}$ \\
\hline Neonatal Mg level $(\mathrm{mg} / \mathrm{dl})$ & $1.8(1.6-2.1)$ & $2.9(2.3-3.6)$ & $<0.001$ \\
\hline RDS & $66(91.8)$ & $93(85.3)$ & 0.248 \\
\hline Hypotension during the first week & $43(59.7)$ & $55(50.5)$ & 0.228 \\
\hline Ibuprofen during the first week & $24(33.3)$ & $38(34.9)$ & 0.874 \\
\hline Treated PDA & $42(58.3)$ & $66(60.6)$ & 0.877 \\
\hline NEC & $12(16.7)$ & $13(11.9)$ & 0.386 \\
\hline Surgical NEC & $8(11.1)$ & $6(5.6)$ & 0.256 \\
\hline SIP & $4(5.6)$ & $0(0)$ & 0.024 \\
\hline Meconium obstruction requiring & $4(5.6)$ & $5(4.6)$ & 0.743 \\
\hline surgery & & $11(10.1)$ & 0.033 \\
\hline Intestinal morbidities requiring surgery & $16(22.2)$ & $45(41.7)$ & 0.540 \\
\hline Moderate to severe BPD & $34(47.2)$ & $10(9.2)$ & 1.000 \\
\hline Postnatal steroid for BPD & $7(9.7)$ & $25(22.9)$ & 0.228 \\
\hline Sepsis & $23(31.9)$ & $13(11.9)$ & 0.196 \\
\hline IVH $\geq$ grade 3 & $4(5.6)$ & $33(30.3)$ & 0.501 \\
\hline ROP operation & $18(25)$ & $29(26.6)$ & 0.404 \\
\hline Mortality & $24(33.3)$ & $13(3-35)$ & 0.192 \\
\hline Invasive ventilation duration & $16(4-50.5)$ & $18(14-27)$ & 0.221 \\
\hline Time to full feeding & $21(15-31)$ & 5 & \\
\hline
\end{tabular}

$\mathrm{MgSO}_{4}$, magnesium sulfate; RDS, respiratory distress syndrome; PDA, patent ductus arteriosus; NEC, necrotizing enterocolitis; SIP, spontaneous intestinal perforation; BPD, bronchopulmonary dysplasia; IVH, intraventricular hemorrhage; ROP, retinopathy of prematurity

Values are expressed as $\mathrm{N}(\%)$ or Median (interquartile range)

The univariate regression analysis showed that low GA, treated PDA and antenatal $\mathrm{MgSO}_{4}$ were associated with surgical conditions of the intestine (Table 3). Small for gestational age (SGA) had an odds ratio of 2.689, without statistical significance $(95 \% \mathrm{Cl} 0.864-8.374, \mathrm{p}=0.088)$. Multivariate logistic regression showed that low GA, SGA and treated PDA were significantly associated with surgical conditions of the intestine, while the association of maternal $\mathrm{MgSO}_{4}$ became insignificant (adjusted OR 0.543, 95\% Cl 0.167-1.030). When logistic analysis was conducted in the subgroup of those with $\mathrm{GA}<26$ weeks, maternal $\mathrm{MgSO}_{4}$ was associated with surgical conditions of the intestine (adjusted OR $0.234,95 \% \mathrm{Cl} 0.060-0.922$ ). The multivariate logistic regression analysis in the total population showed 
that duration of antenatal $\mathrm{MgSO}_{4}$ use was associated with surgical conditions of the intestine, while cumulative dose of $\mathrm{MgSO}_{4}$, maternal $\mathrm{Mg}$ level and neonatal $\mathrm{Mg}$ level had no associations with surgical conditions of the intestine (Table 4).

Table 3

Univariate and multivariate regression analyses for intestinal morbidities requiring surgery

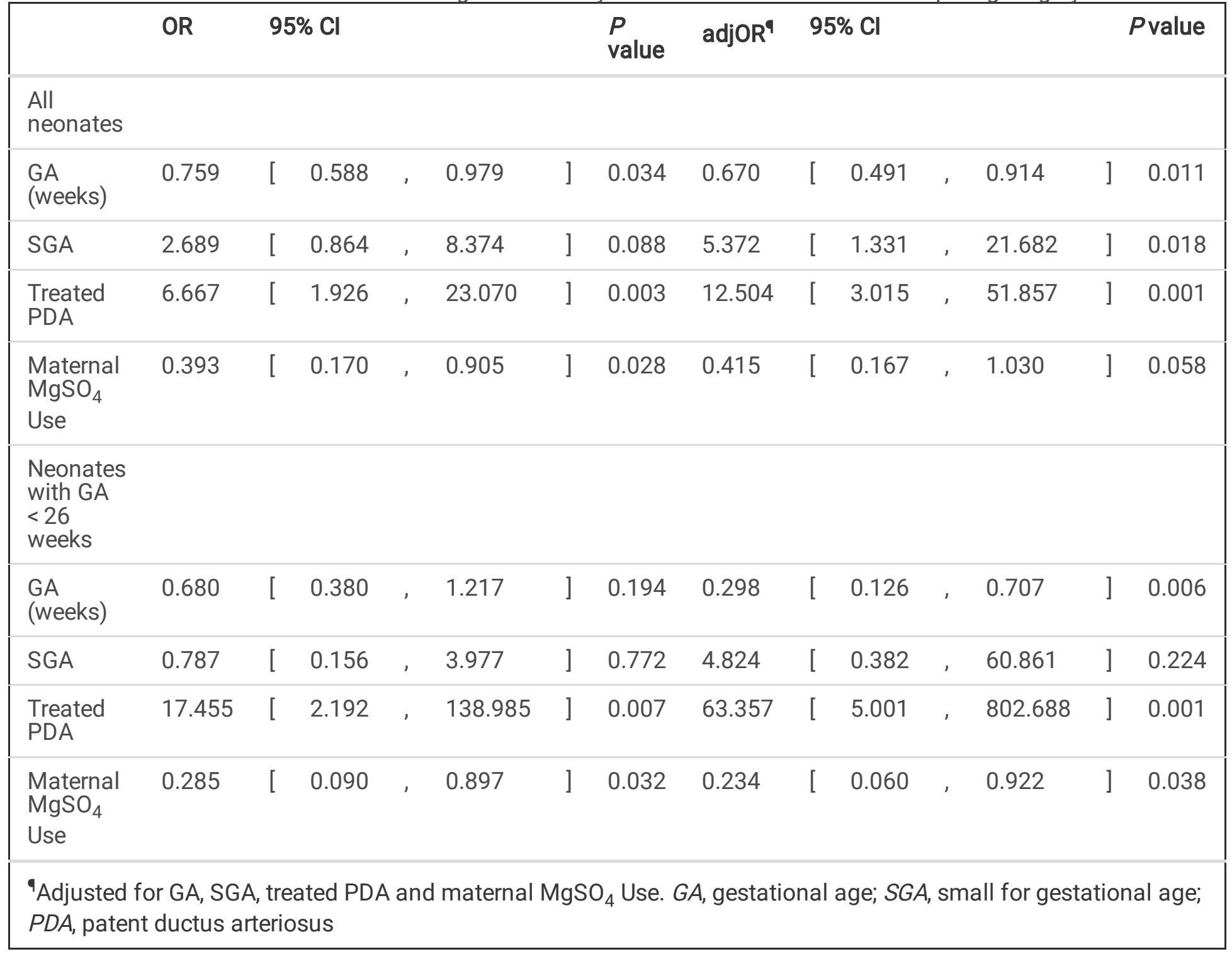


Table 4

Univariate and multivariate logistic regression analyses for magnesium-related factors for intestinal morbidities requiring surgery

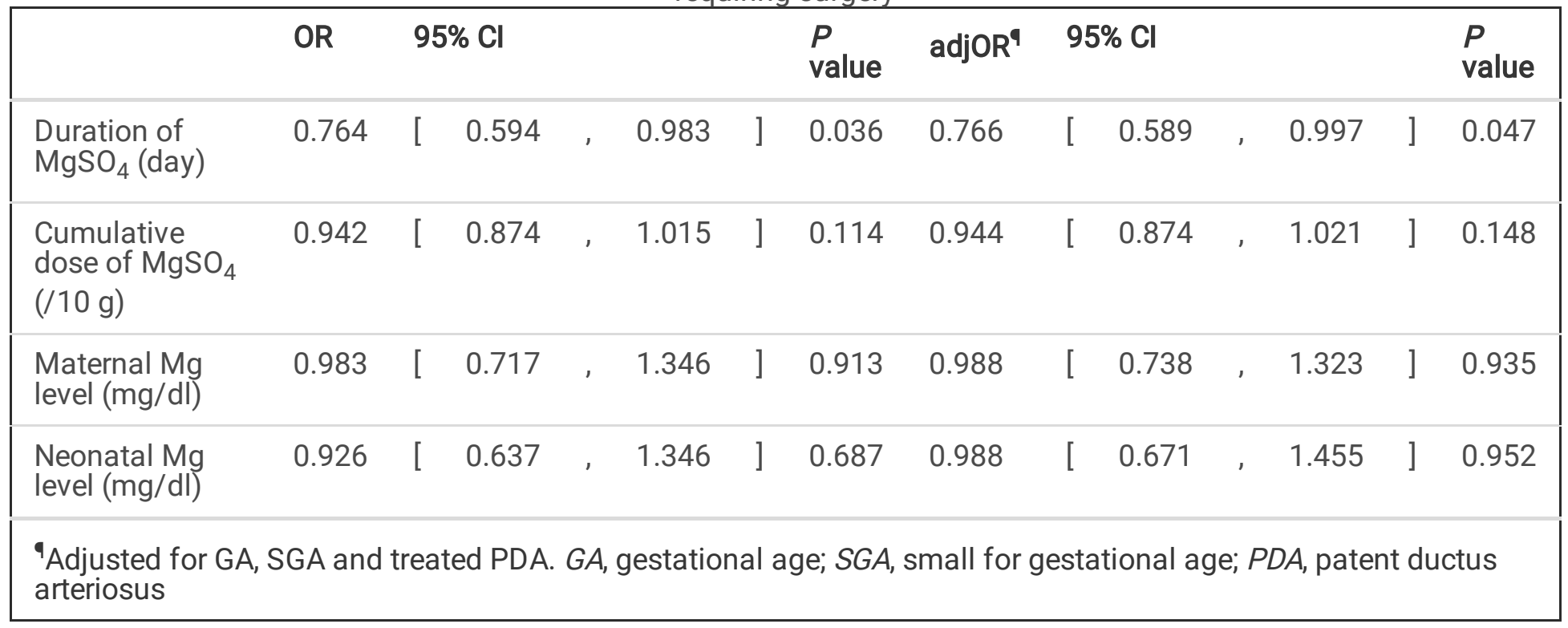

\section{Discussion}

The current study showed that antenatal $\mathrm{MgSO}_{4}$ was associated with low incidence of intestinal morbidities requiring surgery in preterm infants with GA less than 26 weeks. In the total study population, duration of exposure to antenatal $\mathrm{MgSO}_{4}$ was associated with decreased risk of intestinal injury needing surgery. There were no differences in mortality and other morbidities such as RDS, IVH and BPD between infants with and without antenatal $\mathrm{MgSO}_{4}$.

Antenatal $\mathrm{MgSO}_{4}$ has been used widely according to maternal and fetal conditions. Since benefits in terms of the neurodevelopmental outcomes were found in prospective randomized trials [2,3], antenatal $\mathrm{MgSO}_{4}$ is now recommended for fetal neuroprotection in anticipation of preterm delivery in very preterm infants [17]. As the use of antenatal $\mathrm{MgSO}_{4}$ has been highlighted, concerns have been raised regarding the neonatal adverse effects of antenatal $\mathrm{MgSO}_{4}$ because magnesium can block calcium entry into cells, leading to muscle weakness and intestinal atony in the offspring.[10]

A clinical study showed a significant negative relationship between the mean blood flow velocity and the time from birth to the blood flow velocity measurement in antenatal $\mathrm{MgSO}_{4}$-exposed infants.[18] In the secondary analysis of a prospective study, antenatal exposure to $\mathrm{MgSO}_{4}$ was associated with death or severe NEC in infants with a GA less than 26 weeks. $[2,10]$ Furthermore, a study of historical comparisons by Rattray et al reported that antenatal $\mathrm{MgSO}_{4}$ was associated with SIP and death.[12]

However, another secondary analysis of a prospective trial reported that newborns with higher magnesium levels did not show any adverse non-neurological effects.[19] Moreover, a meta-analysis of 5 randomized controlled studies concluded that there were no statistically significant differences in neonatal secondary outcomes, such as IVH, periventricular leukomalacia, NEC, RDS, ROP or chronic lung disease.[20]

In the aforementioned secondary analysis study, although the combined outcome of death and severe NEC was associated with maternal antenatal $\mathrm{MgSO}_{4}$ administration in infants who were GA less than 26 weeks, NEC alone was not associated with antenatal $\mathrm{MgSO}_{4}$.[10] Caution should be taken in the interpretation of the combined 
outcome of NEC and death because the two conditions were not competitive as death and BPD. Although Rattray et al reported the association between antenatal $\mathrm{MgSO}_{4}$ and SIP, but SGA was not included in the analysis.[12] As the development of intestinal morbidities may be influenced by various causes, factors such as GA, SGA and medication history should be considered and coanalyzed to investigate factors associated with these conditions. For instance, SIP was associated with intrauterine growth restriction and PDA with delayed meconium passage in VLBW infants. $[21,22]$

Although this was a retrospective study, the cumulative dose of antenatal $\mathrm{MgSO}_{4}$, duration of antenatal $\mathrm{MgSO}_{4}$ and level of magnesium were calculated and analyzed thoroughly. Factors associated with intestinal morbidities such as GA, SGA, and treated PDA were also reviewed. The results of the present study are consistent with the report from a nationwide database from North America, reporting that antenatal $\mathrm{MgSO}_{4}$ exposure in extremely preterm neonates was associated with reduced risk of a combined outcome of death, NEC and SIP.[23] In a retrospective study from a tertiary-level NICU, cumulative dose of $\mathrm{MgSO}_{4}$ was associated with a combined outcome of death, NEC and SIP.[24] Although a protective role of antenatal $\mathrm{MgSO}_{4}$ has been raised, the physiologically beneficial effect of magnesium on the intestine of preterm infants is not yet fully understood. One study of grass carp showed that magnesium deficiency suppressed the growth and damaged the intestinal structural integrity of the fish.[25] A preclinical study of mice demonstrated that prophylactic oral administration of magnesium ameliorates induced colitis through the inhibition of colonic mast cell activation.[26]

This was a single-center retrospective design, and the indications for antenatal $\mathrm{MgSO}_{4}$ included not only neuroprotection but also preterm labor. However, the dosages of the antenatal $\mathrm{MgSO}_{4}$ treatments for preterm labor and for neuroprotection were similar in our institution, and the data regarding duration, cumulative dosage and level of serum magnesium were reviewed. Mothers with preeclampsia, an important indication for antenatal $\mathrm{MgSO}_{4}$, were excluded because the maternal environment in this condition can affect vascular development of the intestine.[27, 28]

\section{Conclusions}

This retrospective cohort study suggested the benefit of antenatal $\mathrm{MgSO}_{4}$ in the reduction of intestinal injury requiring surgical intervention in extremely preterm infants in a duration-dependent manner, especially in those with a GA less than 26 weeks at birth. Further study with a large population might be required to clarity the beneficial effect of antenatal $\mathrm{MgSO}_{4}$.

\section{Abbreviations}

$\mathrm{MgSO}_{4}$

antenatal magnesium sulfate; NEC:necrotizing enterocolitis; GI:gastrointestinal; SIP:spontaneous intestinal perforation; MO:meconium obstruction; PDA:patent ductus arteriosus; BPD:bronchopulmonary dysplasia; IVH:intraventricular hemorrhage; ROP:retinopathy of prematurity; GA:gestational age; SGA:small for gestational age

\section{Declarations}

\section{Ethics approval and consent to participate}

This study protocol was reviewed and approved by the Institutional Review Board of the Seoul National University Hospital (No. 1904-069-1026). Written informed consent was obtained from the parents of the participants. 


\section{Consent for publication}

Not applicable

\section{Availability of data and materials}

The datasets used and analyzed during the current study are available from the corresponding author on reasonable request.

\section{Competing interests}

All authors declare that they have no competing interests

\section{Funding}

This work was supported by the Basic Science Research Program through the National Research Foundation of Korea (NRF) funded by the Ministry of Education (NRF-2019R1D1A1B04030931).

\section{Author contributions}

Seh Hyun Kim designed the study, performed data analysis and drafted the manuscript. Yoo-Jin Kim, Seung Hyun Shin, and Hannah Cho helped to collect and interpret the data. Seung Han Shin designed the study, performed data analysis, interpreted the data and gave final approval of the version to be published. Ee-Kyung Kim and Han-Suk Kim monitored the study and gave final approval of the version to be published. Subeen Hong helped to collect and interpret the data. Seung Mi Lee helped to design the study and gave final approval of the version to be published.

\section{Acknowledgements}

Not applicable

\section{References}

1. Duley L, Gulmezoglu AM, Chou D. Magnesium sulphate versus lytic cocktail for eclampsia. Cochrane Database Syst Rev 2010(9):CD002960.

2. Rouse DJ, Hirtz DG, Thom E, Varner MW, Spong CY, Mercer BM, lams JD, Wapner RJ, Sorokin Y, Alexander JM, et al. A randomized, controlled trial of magnesium sulfate for the prevention of cerebral palsy. N Engl J Med. 2008;359(9):895-905.

3. Crowther CA, Hiller JE, Doyle LW, Haslam RR. Australasian Collaborative Trial of Magnesium Sulphate Collaborative G: Effect of magnesium sulfate given for neuroprotection before preterm birth: a randomized controlled trial. JAMA. 2003;290(20):2669-76.

4. Marret S, Marpeau L, Zupan-Simunek V, Eurin D, Leveque C, Hellot MF, Benichou J. group Pt: Magnesium sulphate given before very-preterm birth to protect infant brain: the randomised controlled PREMAG trial*. BJOG. 2007;114(3):310-8. 
5. Magpie Trial Follow-Up Study

Magpie Trial Follow-Up Study. Collaborative G: The Magpie Trial: a randomised trial comparing magnesium sulphate with placebo for pre-eclampsia. Outcome for children at 18 months. BJOG 2007, 114(3):289-299.

6. Committee Opinion. No 652: Magnesium Sulfate Use in Obstetrics. Obstet Gynecol. 2016;127(1):e52-3.

7. Magee L, Sawchuck D, Synnes A, von Dadelszen P. Magnesium Sulphate For Fetal Neuroprotection Consensus C, Maternal Fetal Medicine C: SOGC Clinical Practice Guideline. Magnesium sulphate for fetal neuroprotection. J Obstet Gynaecol Can. 2011;33(5):516-29.

8. Shepherd E, Salam RA, Middleton P, Makrides M, Mclntyre S, Badawi N, Crowther CA. Antenatal and intrapartum interventions for preventing cerebral palsy: an overview of Cochrane systematic reviews. Cochrane Database Syst Rev. 2017;8:CD012077.

9. Doyle LW, Crowther CA, Middleton P, Marret S, Rouse D. Magnesium sulphate for women at risk of preterm birth for neuroprotection of the fetus. Cochrane Database Syst Rev 2009(1):CD004661.

10. Kamyar M, Clark EA, Yoder BA, Varner MW, Manuck TA. Antenatal Magnesium Sulfate, Necrotizing Enterocolitis, and Death among Neonates < 28 Weeks Gestation. AJP Rep. 2016;6(1):e148-54.

11. Mittendorf R, Dambrosia J, Pryde PG, Lee KS, Gianopoulos JG, Besinger RE, Tomich PG. Association between the use of antenatal magnesium sulfate in preterm labor and adverse health outcomes in infants. Am $\mathrm{J}$ Obstet Gynecol. 2002;186(6):1111-8.

12. Rattray BN, Kraus DM, Drinker LR, Goldberg RN, Tanaka DT, Cotten CM. Antenatal magnesium sulfate and spontaneous intestinal perforation in infants less than 25 weeks gestation. J Perinatol. 2014;34(11):819-22.

13. Shalabi M, Mohamed A, Lemyre B, Aziz K, Faucher D, Shah PS. Canadian Neonatal Network I: Antenatal Exposure to Magnesium Sulfate and Spontaneous Intestinal Perforation and Necrotizing Enterocolitis in Extremely Preterm Neonates. Am J Perinatol. 2017;34(12):1227-33.

14. Bell MJ, Ternberg JL, Feigin RD, Keating JP, Marshall R, Barton L, Brotherton T. Neonatal necrotizing enterocolitis. Therapeutic decisions based upon clinical staging. Annals of surgery. 1978;187(1):1-7.

15. Garza-Cox S, Keeney SE, Angel CA, Thompson LL, Swischuk LE. Meconium obstruction in the very low birth weight premature infant. Pediatrics. 2004;114(1):285-90.

16. Cho HH, Cheon JE, Choi YH, Lee SM, Kim WS, Kim IO, Shin SM, Kim EK, Kim HS, Choi JH, et al. Ultrasound-guided contrast enema for meconium obstruction in very low birth weight infants: Factors that affect treatment success. Eur J Radiol. 2015;84(10):2024-31.

17. Obstetricians ACo, Gynecol GJO. Committee Opinion No 652. Magnesium sulfate use in obstetrics. 2016, 127(1):e52-e53.

18. Havranek T, Ashmeade TL, Afanador M, Carver JD. Effects of maternal magnesium sulfate administration on intestinal blood flow velocity in preterm neonates. Neonatology. 2011;100(1):44-9.

19. Edwards JM, Edwards LE, Swamy GK, Grotegut CA. Effect of Cord Blood Magnesium Level at Birth on Nonneurologic Neonatal Outcomes. Am J Perinatol. 2019;36(1):3-7.

20. Crowther CA, Middleton PF, Voysey M, Askie L, Duley L, Pryde PG, Marret S, Doyle LW, Group A: Assessing the neuroprotective benefits for babies of antenatal magnesium sulphate: An individual participant data metaanalysis. PLoS Med 2017, 14(10):e1002398.

21. Yilmaz Y, Kutman HG, Ulu HO, Canpolat FE, Uras N, Oguz SS, Dilmen U. Preeclampsia is an independent risk factor for spontaneous intestinal perforation in very preterm infants. J Matern Fetal Neonatal Med.

2014;27(12):1248-51.

Page $10 / 11$ 
22. Arnoldi R, Leva E, Macchini F, Di Cesare A, Colnaghi M, Fumagalli M, Mosca F, Torricelli M. Delayed meconium passage in very low birth weight infants. Eur J Pediatr Surg. 2011;21(6):395-8.

23. Downey LC, Cotten CM, Hornik CP, Laughon MM, Tolia VN, Clark RH, Smith PB. Association of in utero magnesium exposure and spontaneous intestinal perforations in extremely low birth weight infants. J Perinatol. 2017;37(6):641-4.

24. Mikhael M, Bronson C, Zhang L, Curran M, Rodriguez H, Bhakta KY. Lack of Evidence for Time or Dose Relationship between Antenatal Magnesium Sulfate and Intestinal Injury in Extremely Preterm Neonates. Neonatology. 2019;115(4):371-8.

25. Wei SP, Jiang WD, Wu P, Liu Y, Zeng YY, Jiang J, Kuang SY, Tang L, Zhang YA, Zhou XQ, et al. Dietary magnesium deficiency impaired intestinal structural integrity in grass carp (Ctenopharyngodon idella). Sci Rep.

2018;8(1):12705.

26. Ohbori K, Fujiwara M, Ohishi A, Nishida K, Uozumi Y, Nagasawa K. Prophylactic Oral Administration of Magnesium Ameliorates Dextran Sulfate Sodium-Induced Colitis in Mice through a Decrease of Colonic Accumulation of P2 × 7 Receptor-Expressing Mast Cells. Biol Pharm Bull. 2017;40(7):1071-7.

27. Bowker RM, Yan X, De Plaen IG. Intestinal microcirculation and necrotizing enterocolitis: The vascular endothelial growth factor system. Semin Fetal Neonatal Med. 2018;23(6):411-5.

28. Perger L, Mukhopadhyay D, Komidar L, Wiggins-Dohlvik K, Uddin MN, Beeram M. Maternal pre-eclampsia as a risk factor for necrotizing enterocolitis. J Matern Fetal Neonatal Med. 2016;29(13):2098-103.

\section{Figures}

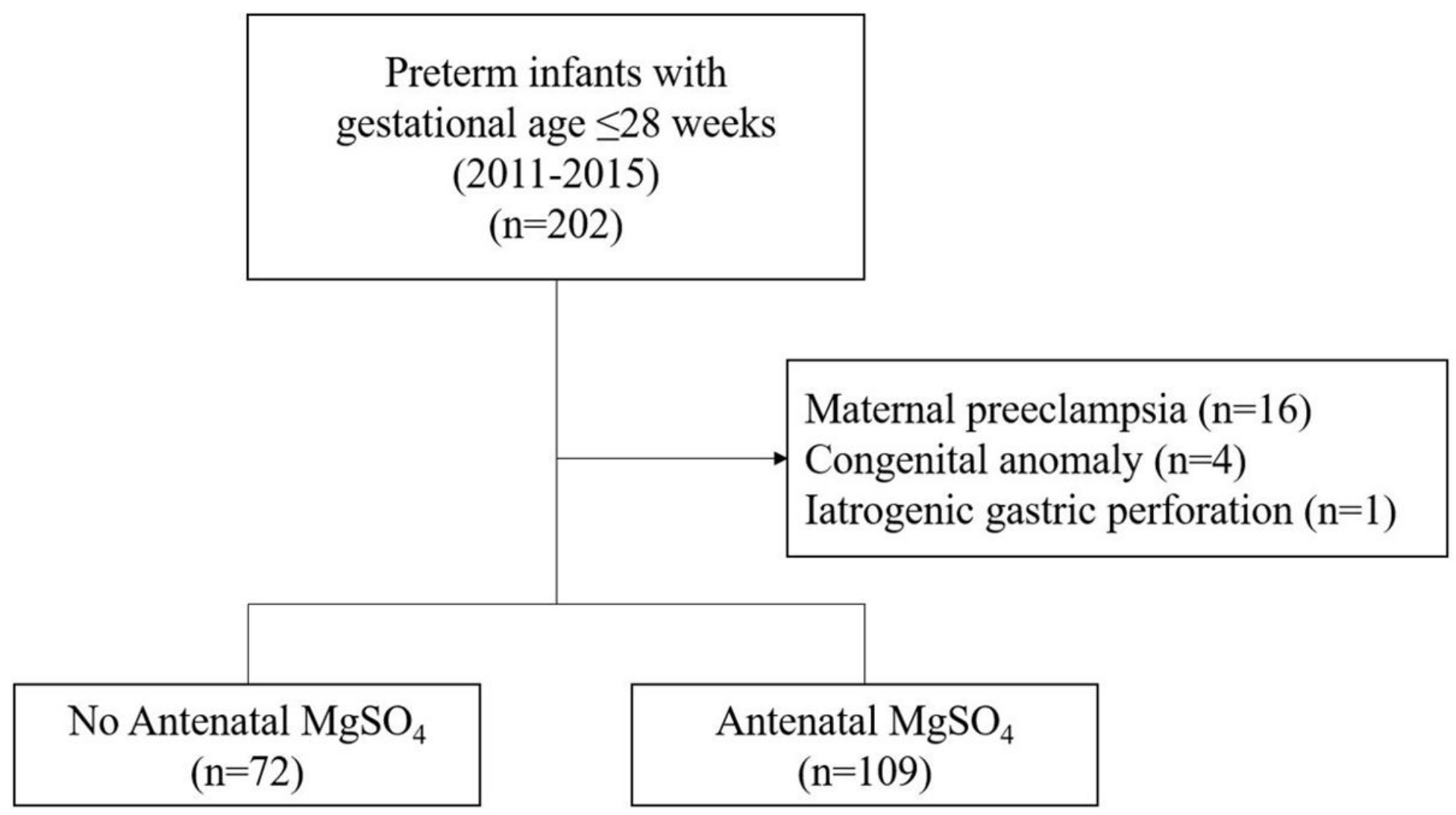

Figure 1

Flow diagram of the study population 